\title{
The 'hybrid' character of the gametes and reproductive tracts of the African shrew, Myosorex varius, supports its classification in the Crocidosoricinae
}

\author{
J. M. Bedford ${ }^{1}$, R. T. F. Bernard ${ }^{2}$ and R. M. Baxter ${ }^{3}$ \\ ${ }^{1}$ Departments of Obstetrics and Gynecology, and Cell Biology and Anatomy, Cornell University Medical \\ College, New York, NY 10021, USA; ${ }^{2}$ Department of Zoology and Entomology, Rhodes University, \\ PO Box 94, Grahamstown, 6140, South Africa; and ${ }^{3}$ Department of Zoology, University of Fort Hare, \\ Private Bag X1314, Alice, 5700, South Africa
}

\begin{abstract}
The Soricidae are generally considered to comprise two subfamilies - Crocidurinae and Soricinae - each of which has distinctive reproductive characteristics. Although Myosorex varius is classified as a crocidurine, the features of its reproductive system call that classification into question. Compared with three other shrew genera, Myosorex exhibited a number of specific features including a relatively prolonged time (about $22 \mathrm{~h}$ ) for ovulation to be induced by hCG injection and the smallest diameter $(75 \mu \mathrm{m})$ recorded for any mammal egg. Moreover, the relative testis mass and the number of epididymal spermatozoa were somewhat greater than in some other shrews studied recently. However, many reproductive features in Myosorex have a 'hybrid' character. The glans penis has spines similar to those evident in crocidurines but absent in soricines, yet the accessory sperm storage site, midway along the vas deferens, is similar to that in soricine shrews. The ultrastructure of Myosorex spermatozoa was primarily soricine, despite an unduly large acrosome, which reaches its apogee in the Crocidurinae. Whereas the Fallopian tube displays a crocidurine-type isthmus characterized by deep crypts throughout, the ampulla is richly endowed with ciliated crypts, which in soricines contain spermatozoa. The first polar body persists in the Myosorex ovum, as it does in the soricines Cryptotis and Blarina, but not in the crocidurine Suncus and Crocidura. However, the cumulus oophorus of Myosorex appears largely crocidurine by virtue of its persistent intercellular junctions, long term stability, and the absence of a matrix, lacking only the unique perizonal space that finally characterizes the cumulus of the crocidurines, Suncus and Crocidura. The 'hybrid' character of the reproductive system of Myosorex is more consistent with the proposal that the genus is a survivor of a primitive subfamily - the Crocidosoricinae - from which present day Soricinae and Crocidurinae have arisen.
\end{abstract}

\section{Introduction}

The evolution of therian mammals has seen the advent of several biologically novel features in the male and female reproductive tracts, in the design and behaviour of their gametes, and in the relationship of one to the other. Among advanced mammals, these features in the male include the scrotal condition, a variable development of different accessory glands, and the dependence of sperm maturation and, therefore, fertilizing ability on some essential factor(s) elaborated by the epididymis. Furthermore, storage of spermatozoa in the lower region of the epididymis is unusual in its acute dependence on testicular androgen and the lower temperature of the scrotum. Among the novel features seen in the female, spermatozoa at the site of fertilization in the ampulla of the oviduct need to

Received 12 June 1997. have undergone capacitation before they can fertilize, and, only in Eutheria, spermatozoa then face the cumulus oophorus, a mass of granulosa cells usually within a proteoglycan matrix, before negotiating the prominent zona pellucida around the tiny egg. The eutherian sperm head has an unusual flat, keratinoid nucleus and a stable posterior (equatorial) segment of acrosome, the plasma membrane over which provides a unique locus of fusion with the oolemma (see Bedford, 1991), which is perhaps related to the mode of its penetration through the unusually thick egg coat.

In the hope that particular comparative situations in more primitive mammals might provide useful insights into the significance of some of these developments, we have begun to study the Insectivora, specifically shrews. These have certain tooth and skull features indicating that they are mammals most closely related to the progenitors of modern Eutheria. After early histological studies of reproductive tracts in Sorex 


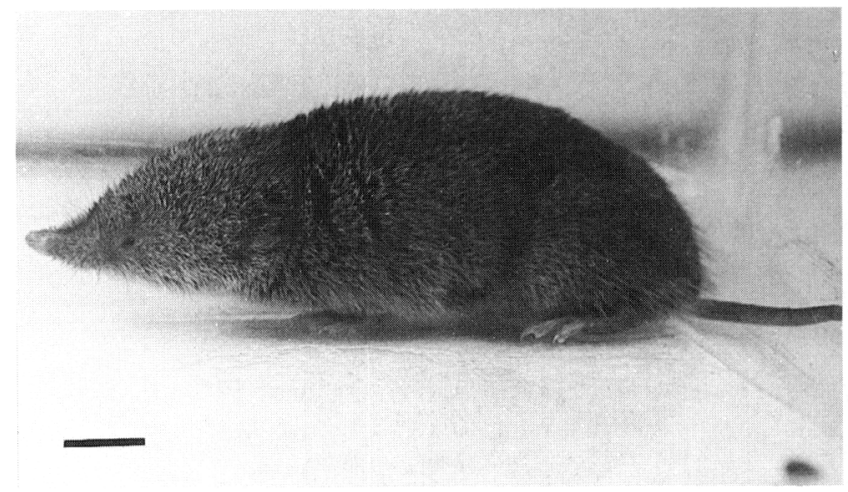

Fig. 1. Adult female Myosorex varius. Scale bar represents $1 \mathrm{~cm}$.

(Brambell, 1935a, b) and in Blarina (Pearson, 1944), the structure of the gametes and their behaviour leading to fertilization have recently been described in three other genera (Suncus, Crocidura and Cryptotis). However, not only have such shrews been found to possess unusual features with regard to sperm structure, the disposition of spermatozoa in the oviduct, and the form and behaviour of the cumulus oophorus, but also the very few species studied display a considerable diversity of such features according to the subfamily, the Crocidurinae and the Soricinae (Bedford et al., 1997a-d). Thus, so far, this line of enquiry has provided more questions than answers.

Since current opinion recognizes about 20 genera (Hutterer, 1985), an understanding of the events in more than the three genera recently examined might provide a clearer overall picture of conception in shrews. Therefore, we have investigated the gametes and reproductive tracts of Myosorex varius, a reputedly crocidurine African shrew. The genus Myosorex is believed to comprise 12 species (Hutterer, 1985), none of which has been examined in this regard. Myosorex is generally classified as crocidurine based on its lack of tooth pigmentation, on continuous articular facets on the mandibular condyle (Repenning, 1967), on anatomical structures related to habitat and life-style (Hutterer, 1985), and on the 'caravanning' behaviour of young (Baxter and Lloyd, 1980). Therefore, since it has been difficult on occasion to classify particular shrews (Martin, 1967; Mori et al., 1991) it was anticipated that such an examination of Myosorex might also help to establish further archetypal crocidurine features useful for systematic studies.

\section{Materials and Methods}

Shrews were trapped in November and December in the vicinity of Grahamstown, and of the University of Fort Hare, Alice, in the Eastern Cape, South Africa. Observations were made on 10 males and 13 females. The conditions of their maintenance were in accordance with protocols approved by the Ethical Standards Committee of Rhodes University. They were housed individually at about $24^{\circ} \mathrm{C}$ in a $14 \mathrm{~h}$ light: $10 \mathrm{~h}$ dark regimen, in aquaria with earth floors, with shredded paper and tubes for shelter, and with canned dog food and water ad libitum. Females were given an i.p. injection of 40 i.u. hCG (Profasi, Serono) to induce ovulation, and were then placed
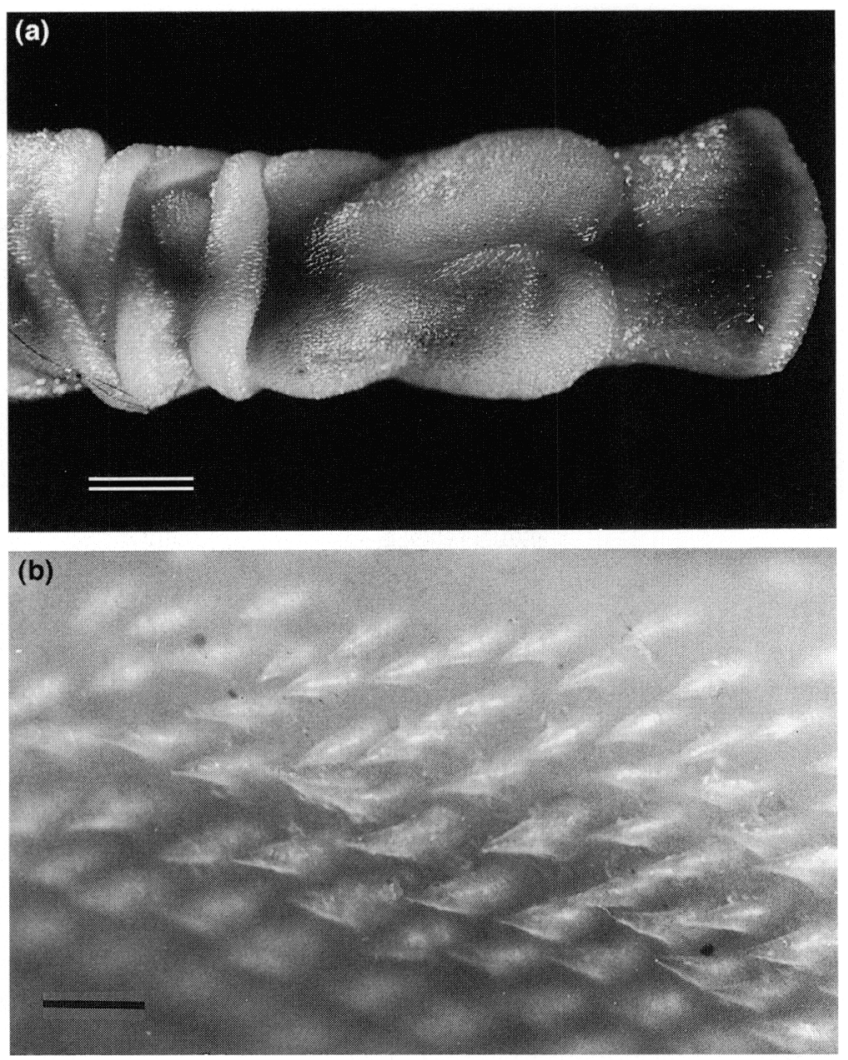

Fig. 2. The extruded penis of Myosorex varius displays (a) a blunted form with bilateral skin swellings overlying a haematic sinus in the posterior glans region and (b) a dense complement of spines that extends to the external meatus. Scale bar represents (a) $1 \mathrm{~mm}$ and (b) $90 \mu \mathrm{m}$.

overnight with a male, identifiable as such only by the extrusion of the penis from the cloacal orifice.

Animals were killed with ether. The testis and attached epididymis and vas deferens were excised from the males, and selected regions were fixed for electron microscopy in $2.5 \%$ $(w / v)$ phosphate-buffered glutaraldehyde followed by postfixation in osmium tetroxide, dehydration in alcohols and propylene oxide, with final embedding in an araldite/ $\mathrm{TAAB}$ mixture (Cross, 1989). The structure of spermatozoa was examined in thin sections of tissues from the caput and cauda regions of the epididymis using a transmission electron microscope (TEM). Spermatozoa released from successive regions of the tract into a culture medium of Dulbecco's modified Eagle's medium (DMEM) at $37^{\circ} \mathrm{C}$ were immediately assessed for motility on warm slides using phase contrast optics, and for the swelling response of the sperm nucleus when exposed to $1 \%$ $(w / v)$ SDS. Total counts were made of the sperm populations in the caput plus the corpus, the cauda epididymidis and the vas deferens in two males using an improved Neubauer haemocytometer.

Oviducts and ovaries were excised from the females and dissected free of membranes $17-39 \mathrm{~h}$ after the hCG injection. Ovulation was assessed according to the presence of ripe follicles or of 'mushroom-like' young corpora lutea. Oviducts were mounted onto slides with the cover glass supported by wax spots. After slight flattening the oviducts were scanned, 


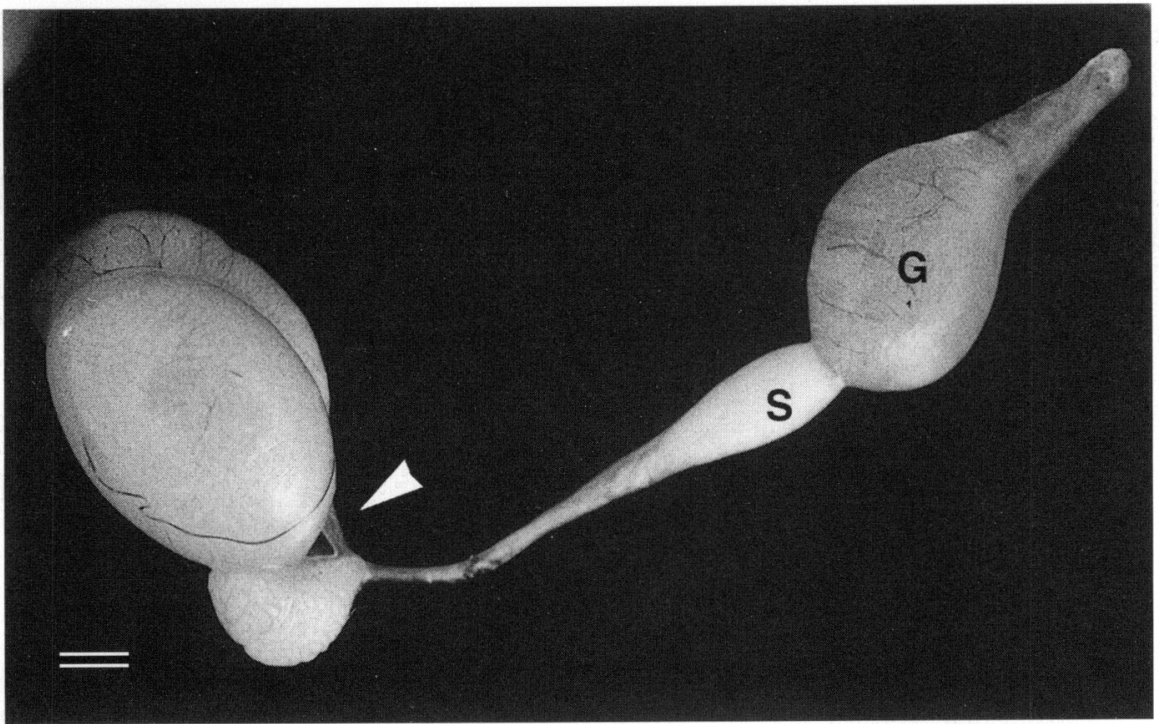

Fig. 3. The special features seen in male reproductive tract of Myosorex varius include an unusual 'vas gland' $(G)$ present in all shrews examined to date, the single duct segment (arrowhead) that connects the corpus to the cauda epididymidis, and the sperm store (S) located on the vas deferens, which seems the likely source of the ejaculated spermatozoa. The scale bar represents $1.2 \mathrm{~mm}$.

using differential interference contrast (DIC) optics, for the character of the isthmus and ampulla, and for the presence and the state of cumulus-oocyte complexes (COCs). In some cases COCs were fixed in situ within a local segment of oviduct ampulla, as described for the male tract, and semi-thin and thin sections of the oviduct and the COCs were studied, respectively, in the light microscope and the TEM. Otherwise, COCs were extruded by stripping the ampulla off with fine forceps, and mounting the COCs again on wax-spot slides for further study.

\section{Results}

The nose-tail length of the adult Myosorex varius is about $10 \mathrm{~cm}$ in natural posture (Fig. 1). The mean bodyweight and mean testis masses were $11.65 \mathrm{~g}$ (range $8.2-15.2 \mathrm{~g}$ ) and $85.9 \mathrm{mg}$ (range $36.0-114.0 \mathrm{mg}$ ), respectively, for males with spermatozoa in the epididymis $(n=7)$. Three other males of bodyweight 7.7-9.6 g were not yet producing spermatozoa. The glans penis was characterized by bilaterally symmetrical skin folds that overlie a haematic sinus, and were covered by a rich array of epithelial spines oriented toward the base of the penis (Fig. 2). The active testis in mature males occupied an inguinal site with the cauda epididymidis preceding it within a cremaster sac. The testis was white, not pigmented green as it is in mature Suncus, Crocidura and Cryptotis. The form of the male tract was unusual in two respects. The epididymis tapered to an extreme degree in the lower corpus region, such that this was connected to the bulbous cauda by a single, almost straight duct segment (Fig. 3). The vas deferens was invested by a large multiloculated gland, as in all other shrews examined so far, but immediately before entering the gland the vas became highly corrugated to create an unusual sperm-filled swelling (Fig. 3). In two males, between 5 and $7 \times 10^{6}$ spermatozoa were counted within each swelling, compared with $10.5-17.5 \times 10^{6}$ spermatozoa per cauda and 6-11 $\times 10^{6}$ spermatozoa counted in each caput plus corpus region. However, in contrast to the cauda, which was consistently filled with spermatozoa, the accessory store in the vas deferens was essentially empty in three of the seven active males examined, suggesting a tendency for its evacuation.

The spermatozoon was characterized by a tail of $85 \mu \mathrm{m}$ and by a head $9.0 \mu \mathrm{m}$ in length, much of which was provided by a long rostral segment of acrosome (Fig. 4a). Spermatozoa, as seen in the TEM, were structurally similar in all regions of the epididymis, except that the plasmalemma tended to balloon, particularly over one face of the acrosome in cauda spermatozoa (Fig. 4b), whereas in caput spermatozoa the membrane was applied closely to the acrosome (Fig. 4c). Despite the unusually large acrosome, there was no 'rim' which reflects the unusual intimate relationship between outer acrosome membrane and plasma membrane seen in crocidurine spermatozoa (Mori ef al., 1991; Bedford et al., 1994). However, in glancing sections, the periacrosomal surface of the plasmalemma was characterized by a regular 'bristly' periodicity not evident over other regions of the sperm surface. The interrupted nature of the perforatorium in some longitudinal sections (Fig. 4 b, c) indicates that it has the barbed configuration seen in spermatozoa of other soricids and some bats (for discussion, see Bedford et al., 1997d). The ultrastructure of the tail of the spermatozoa was notable for the asymmetrically prominent proximal dense fibres 5 and 6 , as seen in other soricid spermatozoa, and outward displacement of fibres 3 and 8 .

In regard to other aspects of epididymal maturation, the great majority of spermatozoa from the upper caput region showed no movement when released into DMEM, in contrast to an almost universal flagellation in those from the corpus 

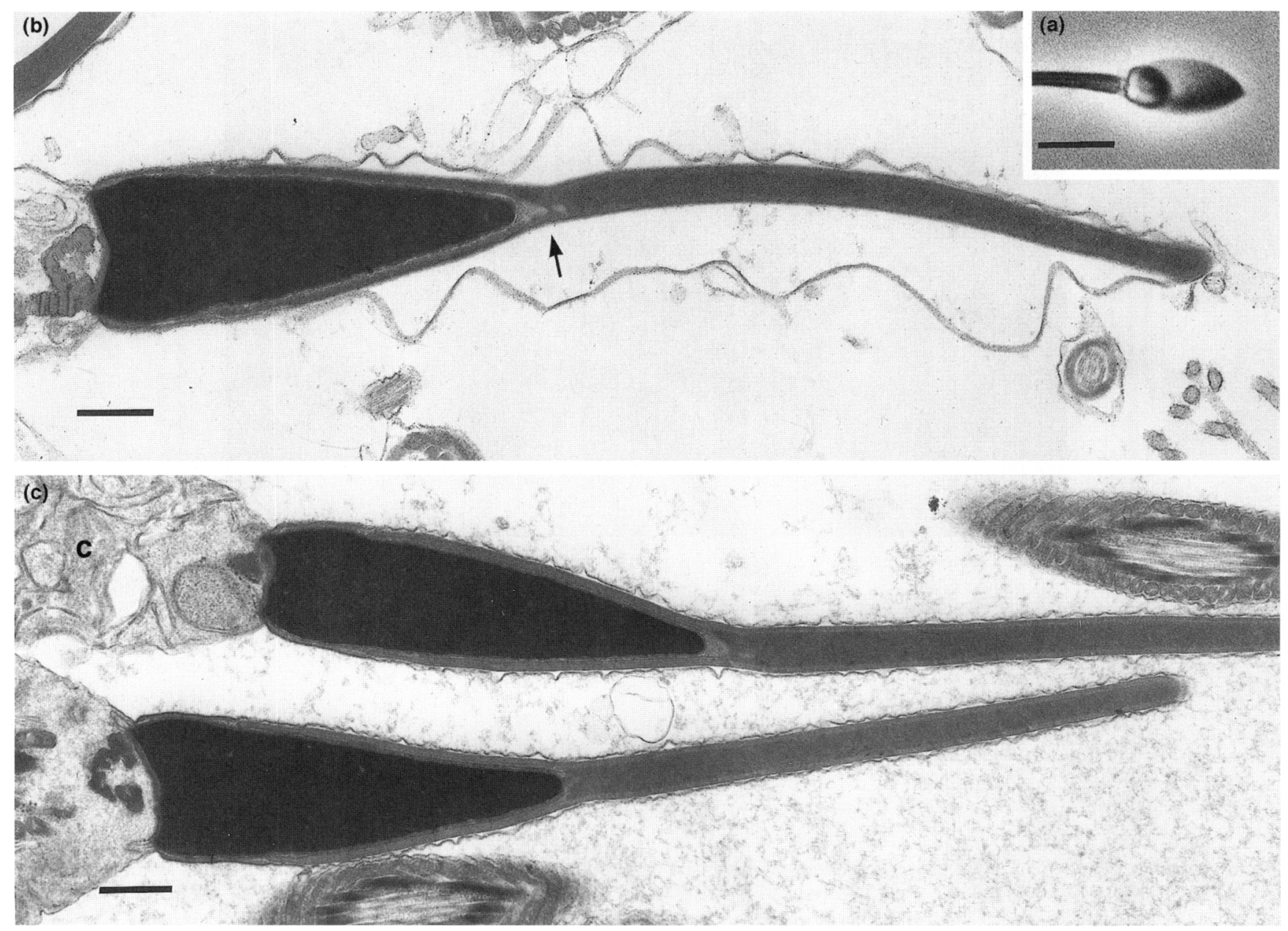

Fig. 4. (a) Phase contrast microscopy of the head of a spermatozoon of Myosorex varius. The rostral segment of the acrosome is exaggerated and extends well beyond the anterior border of the nucleus. Scale bar represents $6.25 \mu \mathrm{m}$. (b) Parasagittal section of a sperm head within the cauda epididymidis using transmission electron microscopy (TEM). Although somewhat asymmetrical in M. varitu, ballooning of the periacrosomal region of the plasmalemma balloons is typical of mature spermatozoa of most mammals and of soricine shrews. The interrupted nature of the perforatorium (arrow) indicates that this has a barbed configuration in the coronal plane. Scale bar represents $0.5 \mu \mathrm{m}$. (c) Parasagittal section through sperm heads within the caput epididymidis of $M$. varius using TEM. The upper head shows evidence of an interrupted perforatorium. In contrast to cauda or vas spermatozoa, the periacrosomal plasmalemma of caput spermatozoa remains closely applied to the underlying acrosome. C: cytoplasmic droplet. Scale bar represents $0.5 \mu \mathrm{m}$.

region and vigorous motility of those from the cauda and the vas deferens. When exposed to $0.02 \%-0.05 \%$ SDS, most of the latter spermatozoa lost all trace of the prominent acrosome. However, whereas the nuclei of vas and cauda spermatozoa were unchanged even in $0.1 \%$ SDS, that concentration of SDS brought a major swelling of the nuclei of spermatozoa from the upper caput epididymidis.

None of the wild-caught females given hCG mated when left overnight with mature males. The general arrangement of the female reproductive tract and ovaries in Myosorex was similar to that in other shrews, typified by Suncus (Bedford et al., 1997c). However, observation of the slightly flattened Fallopian tube (Fig. 5a) with DIC optics revealed not only deep crypts throughout the isthmus, as seen in the crocidurines, Suncus and Crocidura, but also a rich endowment of ciliated crypts throughout most of the ampulla, as seen in soricines such as Cryptotis, Blarina and three Sorex species (O. B. Mock and J. M. Bedford, unpublished observations). Transverse sections of the lower ampulla (Fig. 5b) showed complex epithelial folds that create channels between the ciliated main lumen and the peripherally located ampullary crypts (Fig. $5 \mathrm{c}$ ). As indicated by the occurrence of ovulation or development of a localized follicular vascularity before ovulation, the i.p. injection of hCG had stimulated ovarian follicles in all 13 females examined $17.0 \mathrm{~h}$ or more after the injection, including three females (Nos 12, 18, 20) in which corpora lutea had been counted, but the actual ovulation time had not been monitored. The mean number of follicles stimulated or ovulating was 3.3 per female (range 2.0-6.0). Ovulation did not occur for a relatively long period (about $22 \mathrm{~h}$ ) after hCG (Table 1).

Eggs were surrounded by a dense ball of cumulus cells at ovulation (Fig. 6a), but were readily freed from the shell of the cumulus with 30 gauge needles. They were only $75 \mu \mathrm{m}$ in diameter at the zona surface as measured directly from a 
(a)
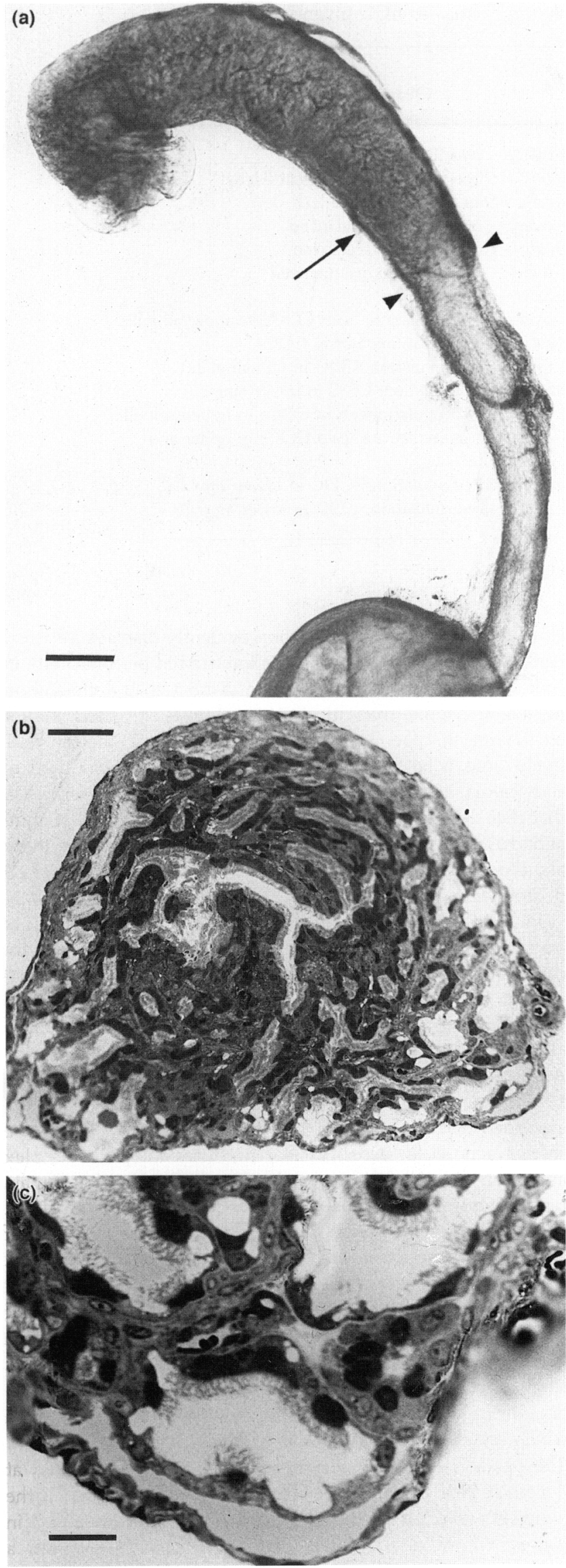

vernier scale. The COCs were closely surrounded by ampullary folds within the living oviducts and in semi-thin sections of the ampulla (Fig. 6b) as visualized in situ with DIC optics. The eggs studied always exhibited a first polar body even $18 \mathrm{~h}$ after ovulation (Fig. 6c). The cumulus oophorus had no intercellular matrix (Fig. 6d), and neighbouring cells were associated by way of desmosome-like complexes (Fig. 6e). The COCs gradually moved down the ampulla during the first hours after ovulation, but there was no change in the appearance of the cumulus oophorus around unfertilized eggs, with the exception of one of three COCs lying together in one ampulla (Fig. 6c) $18 \mathrm{~h}$ after ovulation in female No. 10.

\section{Discussion}

Any apparent trends or groupings in regard to reproductive characteristics of shrews must be viewed with caution owing to the very small number of the extant species that have been studied in this way. None the less, it is clear that various details of their reproductive tracts and the form and behaviour of their gametes differ quite obviously from one shrew to another, and 'diversity' already seems an appropriate first watchword for the reproductive system in shrews. So far, these differences have tended to distinguish the crocidurine subfamily, exemplified by Suncus and Crocidura (Bedford et al., 1994, 1997a, c, d; T. Mori and J. M. Bedford, unpublished observations), from the soricine subfamily as represented by Cryptotis (Bedford et al., 1997b), Blarina and, tentatively so far, three species of Sorex (O. B. Mock and J. M. Bedford, unpublished). Therefore, it was our expectation that Myosorex, as a putative member of the Crocidurinae, would help to substantiate as definitively "crocidurine' some unusual reproductive characteristics manifested by Suncus and Crocidura, but not by indisputable soricines such as Sorex, Blarina and Cryptotis. These apparently crocidurine traits in Suncus and Crocidura include: (a) a giant acrosome whose plasmalemmal-outer acrosome membrane complex forms an unusual stable rim; (b) a Fallopian tube isthmus defined by deep crypts that house spermatozoa, and (c) an inert, long-lived cumulus oophorus that retreats from the zona pellucida to create a closed perizonal space that is the repository of cumulus-involved spermatozoa, motile or immotile, but

Fig. 5. (a) A Fallopian tube from Myosorex varius at its resting length after removal of mesosalpinx and membranes of the ovarian bursa as seen using differential interference contrast optics. Arrowheads mark the isthmo-ampullary junction. The isthmus is defined throughout by deep, essentially cilia-free, epithelial crypts, not evident at this magnification. The somewhat wider ampulla is distinguished along all but the uppermost region by a rich complement of peripherally located ciliated crypts. The arrow designates the level of the transverse section shown in (b). Scale bar represents $0.4 \mathrm{~mm}$. (b) A transverse section of the ampulla of a Fallopian tube from $M$. varius, stained with Toluidine blue, illustrates the way the avenues between the epithelial folds that come from a central flat duct lumen eventually communicate with richly ciliated crypts situated at the periphery. Scale bar represents $660 \mu \mathrm{m}$. (c) A peripheral segment of a transverse section, such as that in (b) illustrating in more detail the typical character of the ciliated crypts that are distributed throughout most of the ampulla. Scale bar represents $210 \mu \mathrm{m}$. 
Table 1. The ovulation response of Myosorex varius to hCG given i.p.

\begin{tabular}{|c|c|c|c|c|}
\hline $\begin{array}{l}\text { Female } \\
\text { no. }\end{array}$ & $\begin{array}{c}\text { Bodyweight } \\
\text { (g) }\end{array}$ & $\begin{array}{l}\text { Time after } \\
\text { hCG }(\mathrm{h})\end{array}$ & Ovulation & Ovarian response \\
\hline 3 & 6.35 & 17.0 & - & Right ovary - two follicles vascularized \\
\hline 9 & 8.20 & 20.5 & - & Left ovary - three ripe follicles: eggs at Met II \\
\hline 16 & 12.80 & 20.8 & - & $\begin{array}{l}\text { Left ovary - four follicles vascularized } \\
\text { Right ovary - one follicle vascularized }\end{array}$ \\
\hline $6(P)$ & 11.15 & 21.0 & - & Left ovary - two follicles vascularized \\
\hline $4(\mathrm{P})$ & 9.85 & 22.0 & - & Right ovary - three follicles vascularized \\
\hline 13 & 12.50 & 22.0 & + & $\begin{array}{l}\text { Left ovary - one ovulation } \\
\text { Right ovary - one ovulation; both COCs in upper ampulla }\end{array}$ \\
\hline 22 & 12.00 & 22.5 & + & $\begin{array}{l}\text { Left ovary - two ovulations; bursal COCs } \\
\text { Right ovary - one ovulation; COC in mid-ampulla }\end{array}$ \\
\hline 23 & 10.85 & 25.0 & + & $\begin{array}{l}\text { Left ovary - one ovulation; COC in upper ampulla } \\
\text { Right ovary - two ovulations; two COCs in upper ampulla }\end{array}$ \\
\hline 11 & 8.15 & 27.5 & + & $\begin{array}{l}\text { Right ovary - two ovulations; two COCs in upper and } \\
\text { lower ampulla }\end{array}$ \\
\hline 10 & 9.23 & 39.0 & + & $\begin{array}{l}\text { Left ovary - three ovulations; COC in lower ampulla } \\
\text { Right ovary - one ovulation; COC in lower ampulla }\end{array}$ \\
\hline
\end{tabular}

(P): late pregnancy. COC: cumulus-oocyte complex.

all lacking acrosomes (Bedford et al., 1994, 1997a, c, d). In addition, the glans penis in both Suncus and Crocidura is covered with spines.

In fact, the character of its reproductive system brings into question the designation of Myosorex as a crocidurine. Myosorex displayed one or two features specific to this genus, such as the relatively long interval, of about $22 \mathrm{~h}$, from hCG treatment to ovulation, compared with $13-15 \mathrm{~h}$ in other shrews studied. Moreover, with a zona diameter of only $75 \mu \mathrm{m}$, the egg of Myosorex seems to displace that of the field vole (Austin, 1957) as the smallest mammalian egg recorded. However, Myosorex also exhibited a complex mix of other reproductive characters that, on the basis of previous observations in other shrews, are part soricine and part crocidurine. These characteristics are summarized in Table 2.

The field of spines over the glans penis in Myosorex is quite common among small mammals. However, while it mimics that in the crocidurines Suncus murinus and Crocidura russula and $C$. dsinezumi (Bedford et al., 1997c; T. Mori and J. M. Bedford, unpublished observations), such spines are absent from soricines such as Blarina (Pearson, 1944), Sorex cinereus, S. palustris, S. longirostris and Cryptotis parva (O. B. Mock and J. M. Bedford, unpublished observations). The spermatozoon of Myosorex evidently undergoes a maturation in the epididymis similar to that in other mammals, at least in regard to its motility and stabilization of the sperm chromatin by covalent ( $-S-S-$ ) bonds (see Bedford, 1991). Moreover, the changing disposition of the plasmalemma from a tight to a ballooned configuration between the caput and cauda regions is reminiscent of that which occurs in fixed spermatozoa from some other mammals, and provides the first indication in a shrew that the sperm membrane is modified during passage through the epididymis. The rather consistent one-sided ballooning of the mature periacrosomal plasmalemma hints at dorsoventral asymmetry, a character shown with surface markers for the spermatozoa of Suncus murinus (Cooper and Bedford, 1976).
However, while the spermatozoon evidently displays a barbed perforatorium (as indicated by the interrupted perforatorium in some sagittal sections), and a more distinct rostral elongation of the acrosome than in soricine shrews, its head is not crocidurine in type. The acrosome of Myosorex, though relatively large, is far smaller than the giant acrosome of Crocidura and Suncus, and it does not resist the concentrations of SDS that theirs do. In addition, the loose disposition of the mature periacrosomal plasmalemma and its 'bristly' surface are more like those of the soricines examined so far (Mori et al., 1991; Bedford et al., 1997b).

In Myosorex, an interesting feature of the male reproductive tract is the local aggregation of spermatozoa in the unusually convoluted distal segment of the vas deferens, which is also seen in various soricines and other shrews (O. B. Mock and J. M. Bedford, unpublished observations). This arrangment is rare in mammals, but has been noted as a feature in the Australian hopping mouse (Breed, 1986; Peirce and Breed, 1989). As suggested for that species, it appears that this expanded distal segment of the vas in Myosorex and soricine shrews acts as an accessory sperm store, and could be the immediate source of spermatozoa in the ejaculate, with gradual replacement of spermatozoa into this region from the cauda epididymidis in the period after ejaculation.

The Fallopian tube of Myosorex has a crocidurine-type isthmus (Bedford et al., 1994, 1997a, c), defined throughout by deep crypts that are absent in the several soricines studied so far. However, its ampulla is endowed with many ciliated crypts similar to those seen in soricines (Cryptotis parva: Bedford et al., 1997b; Blarina brevicauda, Sorex palustris, S. longisrostris, S. cinereus: O. B. Mock and J. M. Bedford, unpublished), but which are absent in Suncus and relatively sparse in Crocidura. The persistence of the first polar body within the ovum in Myosorex is a trait not seen so far in the two crocidurines (where it soon disintegrates) but seen in two soricines (Cryptotis parva: Bedford et al., 1997b; Blarina brevicauda: O. B. Mock 

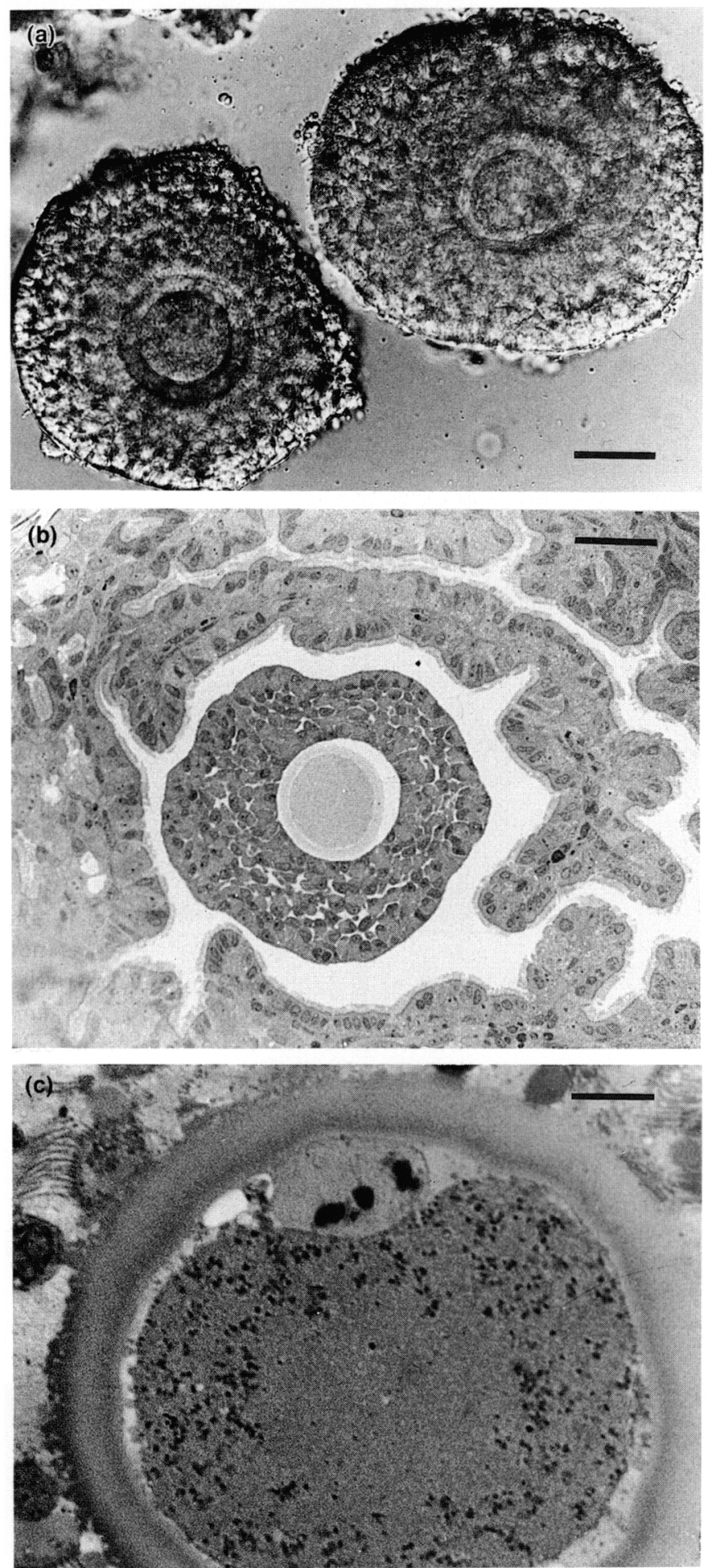
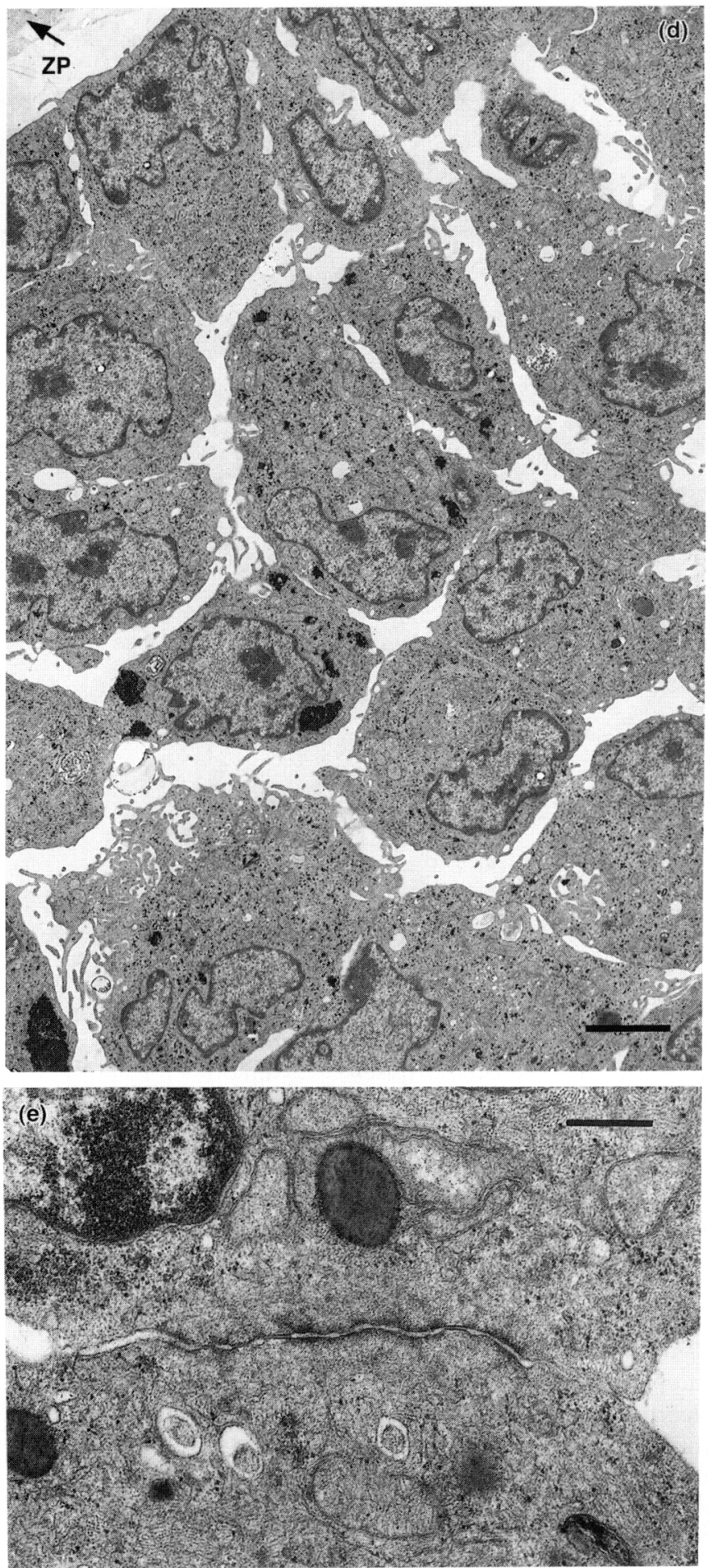

Fig. 6. (a) Two cumulus-oocyte complexes (COCs) from Myosorex vorius extruded from the upper ampulla $22 \mathrm{~h}$ after hCG treatment (that is, at about the time of ovulation) visualized using differential interference contrast optics. The cumulus is ovulated as a matrix-free (non-expanded) dense mass of cells in contrast to that of most mammals. Scale bar represents $50 \mu \mathrm{m}$. (b) Transverse section of a COC, stained with Toluidine blue, in situ in the mid-ampulla, taken about $25 \mathrm{~h}$ after hCG treatment. The intact cumulus is enveloped by epithelial folds. Scale bar represents $45 \mu \mathrm{m}$. (c) Section through an unfertilized tubal egg in the ampulla, fixed $39 \mathrm{~h}$ after hCG (about $18 \mathrm{~h}$ after ovulation) and stained with Toluidine blue. Typically, and in contrast to the crocidurines Suncus and Crocidura, a prominent first polar body remains intact, as it does for many hours after ovulation in the soricines Blarina and Cryptotis. The cumulus is almost dispersed. A cumulus remained around each of two neighbouring unfertilized oocytes located in the same region of this tube. Scale bar represents $9.5 \mu \mathrm{m}$. (d) Segment of the cumulus oophorus of $M$. varins fixed $25 \mathrm{~h}$ after hCG (about $3 \mathrm{~h}$ after ovulation) visualized using transmission electron microscopy (TEM). Each cell associates with its neighbours by way of several junctional complexes. Although intercellular junctional complexes within the cumulus tend to disappear before ovulation in most mammals, these persisted for many hours after ovulation in $M$. varius, as they do in the crocidurines, Suncus and Crocidura. The black granules and larger black deposits in a few cells are believed to represent glycogen. ZP: zona pellucida. Scale bar represents $2.5 \mu \mathrm{m}$. (e) TEM showing the apposed borders of two cumulus cells in M. varius illustrating one of the desmosome-like complexes that probably maintain their relationship. Scale bar represents $0.45 \mu \mathrm{m}$. 
Table 2. Subfamily affinities of some reproductive characteristics seen in Myosorex varius

\begin{tabular}{|c|c|c|}
\hline Character in Myosorex & Soricine type & Crocidurine type \\
\hline Vas deferens sperm store & $\begin{array}{l}\text { Cryptotis parva } \\
\text { Blarina brevicauda } \\
\text { Sorex palustris } \\
\text { Sorex cinereus }\end{array}$ & - \\
\hline Penile spines & - & $\begin{array}{l}\text { Suncus murinus } \\
\text { Crocidura russula } \\
\text { Crocidura dsinezumi }\end{array}$ \\
\hline Sperm head structure & $\begin{array}{l}\text { Cryptotis parva } \\
\text { Blarina brevicauda } \\
\text { Sorex palustris } \\
\text { Sorex cinereus }\end{array}$ & - \\
\hline Crypts in oviduct isthmus & - & $\begin{array}{l}\text { Suncus murinus } \\
\text { Crocidura russula } \\
\text { Crocidura dsinezumi }\end{array}$ \\
\hline Many crypts in oviduct ampulla & $\begin{array}{l}\text { Cryptotis parva } \\
\text { Blarina brevicauda } \\
\text { Sorex palustris }\end{array}$ & - \\
\hline Stable inert cumulus oophorus & - & $\begin{array}{l}\text { Suncus murinus } \\
\text { Crocidura russula }\end{array}$ \\
\hline Persistent first polar body & $\begin{array}{l}\text { Cryptotis parva } \\
\text { Blarina brevicauda }\end{array}$ & - \\
\hline
\end{tabular}

and J. M. Bedford, unpublished observations). Yet the dense cumulus oophorus of Myosorex is almost crocidurine in its long-term inertness, in its intercellular junctions, and in the absence of postovulatory matrix secretion (compare with Cryptotis: Bedford et al., 1997b), lacking only the significant perizonal space that develops as a unique characteristic of the cumulus in the true crocidurines studied (Bedford et al., 1997a, d). How the cumulus behaves in Myosorex after fertilization awaits further study.

Although previous analyses of relationships have invoked penile morphology (Smith and Madkour, 1980), and sperm morphology (Bedford, 1974; Jamieson et al., 1995), reproductive traits have not proved to be particularly useful as a basis for systematic or cladistic analysis (Luckett, 1980; Voss and Linzey, 1981). In the present case, however, reproductive traits do appear to be a useful basis. While the mix of reproductive traits in Myosorex is not consistent with it being classified simply as a crocidurine, they do support Reumer's (1987) proposal that Myosorex is a member of an older subfamily, the Crocidosoricinae, that gave rise to the present day Crocidurinae and Soricinae. The mix of reproductive characteristics is also consistent with the conclusion from recent alloenzyme analyses that Myosorex occupies an intermediate and primitive position in relation to soricines and crocidurines (Maddalena and Bronner, 1992). Finally, it accords with earlier reservations about the place of Myosorex, voiced on the basis of certain dentition and skull features (Meester, 1953; Heim de Balzac and Lamotte, 1956), and, perhaps, with recent observation of metabolic and behavioural traits that differ in certain respects from those of true crocidurines (Brown et al., 1997).
'Difference' is another watchword that characterizes the gametes and reproductive tracts of the Soricidae and in this regard, the primitive status of Myosorex is of particular interest because the unusual reproductive features of shrews may eventually provide insights into some of the general questions raised in the Introduction about mammalian conception. Shrews exhibit novel features with regard to sperm morphology and to the configuration of male accessory glands. Shrews produce relatively few spermatozoa, and with the exception of cows, which have crypts at the uterotubal junction (Hunter, 1995), appear, so far, to be the only example in a eutherian in which the oviduct has differentiated crypts that house spermatozoa. It remains to be determined whether these crypts serve to store spermatozoa or, more likely, to limit the number at the site of fertilization in shrews. Furthermore, in keeping with the very small antrum of the mature ovarian follicle and narrow ampulla of the Fallopian tube, the soricid cumulus differs from that of most mammals in presenting as a dense ball that has no matrix. The indications are that the cumulus may be essential for fertilization in shrews, perhaps by virtue of a role in induction of the acrosome reaction (Bedford et al., 1997a, b, d).

Such information about fertilization and cumulus behaviour has been obtained in other shrews after mating of adapted or captive-bred individuals. In the present series, the strategy of placing recently caught males and females together did not lead to mating. However, the use of captive-bred animals may in the future prove successful in the case of Myosorex, whose unusual features justify further efforts in that regard. $M$. varius presents a distinctly greater testis mass and sperm production, 
and the most elaborate system of sperm crypts in the Fallopian tube seen thus far in any mammal. Finally, its sperm morphology suggests that, as with Cryptotis (Bedford et al., 1997b) and other soricines (O. B. Mock and J. M. Bedford, unpublished), it may be possible to capacitate spermatozoa and fertilize eggs in vitro. Should this be the case, the fact that the cumulus can be dissected easily from newly ovulated eggs will facilitate investigation of the apparently essential role that this vestment has in fertilization in shrews.

Note added in proof. In subsequent studies, a female mated less than $24 \mathrm{~h}$ previously displayed moving spermatozoa in small groups within peripheral ciliated crypts located in the lower ampulla. However, the many active spermatozoa in the isthmus were essentially confined to the central lumen rather than to the crypts, which harbour isthmic spermatozoa in the crocidurines, Suncus and Crocidura. In addition, in vitro fertilization, whilst being possible with spermatozoa from Cryptotis and other soricines, could not be achieved in Myosorex. Under the same conditions (DMEM $+10 \%$ fetal calf serum at $37^{\circ} \mathrm{C}$ in $5 \%$ $\mathrm{CO}_{2}$ ) active Myosorex spermatozoa from the cauda epididymis merely bound to the cumulus of, but did not penetrate, freshly ovulated Myosorex oocytes - a refractoriness observed previously in the crocidurine Suncus murinus (Bedford et al., 1997d).

The authors are grateful to R. H. M. Cross (Rhodes University) for photography and for providing various facilities, and to N. J. Dippenaar (Isteg Scientific Publications) for his critical reading of the manuscript. J. M. Bedford was supported by travel grants from the South African Federal Research Department and by an award from the American Philosophical Society.

\section{References}

Austin CR (1957) Fertilization, early cleavage and associated phenomena in the field vole (Microtus agrestis) Journal of Anatomy 91 1-11

Baxter RM and Lloyd CNV (1980) Notes on the reproduction and postnatal development of the forest shrew Acta Theriologica 25 31-38

Bedford JM (1974) Biology of primate spermatozoa. In Contributions to Primatology pp 97-139 Ed. WP Luckett. S. Karger, Basel

Bedford JM (1991) The co-evolution of mammalian gametes. In A Comparative Overview of Mammalian Fertilization pp 3-35 Eds BS Dunbar and MG O'Rand. Plenum Press, New York

Bedford JM, Cooper GW, Phillips DM and Dryden GL (1994) Distinctive features of the gametes and reproductive tracts of the Asian musk shrew, Suncus murinus. Biology of Reproduction 50 845-854

Bedford JM, Phillps DM and Mover-Lev H (1997a) Novel sperm crypts and behavior of gametes in the Fallopian tube of the white-toothed shrew, Crocidura russula monacha. Journal of Experimental Zoology 277 262-273

Bedford JM, Mock OB and Phillips DM (1997b) The unusual ampullary sperm crypts, and behavior and role of the cumulus oophorus in the oviduct of the least shrew, Cryptotis parva. Biology of Reproduction 56 1255-1267

Bedford JM, Mori T and Oda S (1997c) Ovulation induction and gamete transport in the female tract of the musk shrew, Suncus murinus. Journal of Reproduction and Fertility 110 115-125
Bedford JM, Mori T and Oda S (1997d) The unusual state of the cumulus oophorus and of sperm behaviour within it, in the musk shrew Suncus murinus. Journal of Reproduction and Fertility 110 127-134

Brambell FWR (1935a) Reproduction in the common shrew (Sorex araneus Linnaeus). I. The oestrous cycle of the female Philosophical Transactions of the Royal Society London B 225 1-49

Brambell FWR (1935b) Reproduction in the common shrew (Sorex araneus Linnaeus). Il. Seasonal changes in the reproductive organs of the male Philosophical Transactions of the Royal Society London B 225 51-62

Breed WG (1986) Comparative morphology and evolution of the male reproductive tract in the Australian hydromyine rodents (Muridae) Journal of Zoology $209607-629$

Brown CR, Hunter E and Baxter RM (1997) Metabolism and thermoregulation in the forest shrew Myosorex varius (Soricidae: Crocidurinae) Comparative Biochemistry and Physiology 118A 1285-1290

Cooper GW and Bedford JM (1976) Asymmetry of spermiation and sperm surface charge patterns over the giant acrosome in the musk shrew, Suncus murinus. Journal of Cell Biology $69415-428$

Cross RHM (1989) A reliable epoxy resin mixture and its application in routine biological transmission electron microscpy Micron and Microscopica Acta 20 1-7

Heim de Balsac $\mathrm{H}$ and Lamotte $\mathrm{M}$ (1956) Evolution et phylogenie des Soricides africains. I. La lignee Myosorex-Surdisorex. Mammalia 20 140-167

Hunter RHF (1995) Significance of the epithelial crypts at the bovine utero-tubal junction in the pre-ovulatory phase of sperm regulation Acta Veferinaria Scandinavica $36 \quad 413-421$

Hutterer R (1985) Anatomical adaptations of shrews Mammal Reviews 15 $43-55$

Jamieson BGM, Ausio J and Justine J-L (1995) Advances in Spermatozoal Phylogeny and Taxonomy. Memoires du Museum national d'Histoire naturelle Vol. 166, Paris

Luckett WP (1980) The use of reproductive and developmental features in assessing tupaiid affinities. In Comparative Biology and Evolutionary Relationships of Tree Shrews pp 245-268 Ed. WP Luckett. Plenum Press, New York.

Maddalena T and Bronner G (1992) Biochemical systematics of the endemic African genus Myosorex Gray, 1838 (Mammalia: Soricidae) Israel Journal of Zoology 38 245-252

Martin RA (1967) Notes on the male reproductive tract of Nectogale and other soricid insectivores Journal of Mammalogy 48 664-666

Meester J (1953) The genera of African shrews Annals of the Transvaal Museum 22 205-214

Mori T, Arai S, Shiraishi S and Uchida TA (1991) Ultrastructural observations on spermatozoa of the Soricidae, with special attention to a subfamily revision of the Japanese water shrew Chimarrogale himalayica. Journal of the Mammal Society of Japan 16 1-12

Pearson OP (1944) Reproduction in the shrew (Blarina brevicauda Say) American Journal of Anatomy 75 39-93

Peirce EJ and Breed WG (1989) Light microscopical structure of the excurrent ducts and distribution of spermatozoa in the Autralian rodents Pseudomys australis and Notomys alexis. Journal of Anatomy 162 195-213

Repenning CA (1967) Subfamilies and Genera of the Soricidae Professional Paper of U.S. Geological Survey 565 1-74. United States Government Printing Office, Washington

Reumer JWF (1987) Redefinition of the Soricidae and the Heterosoricidae (Insectivora, Mammalia), with the description of the Crocidosoricinae, a new family of the Soricidae Revue de Paleobiologie 6 189-192

Smith JD and Madkour G (1980) Penial morphology and the question of chiropteran phylogeny. In Proceedings of the Fifth International Bat Research Conference pp 347-365 Eds DE Wilson and AL Gardner. Texas Tech Press, Lubbock, Texas

Voss RS and Linzey AZ (1981) Comparative gross morphology of male accessory glands among neotropical Muridae (Mammalia: Rodentia) with comments on systematic implications Miscellaneous Publications of the Museum of Zoology of the University of Michigan 159 1-4I 